17 Shafrir E, Berman M, Felig P. The endocrine pancreas: diabetes mellitus. In: Felig P, Baxter JD, Broadus AE, Frohman LA, eds. Endocrinology and metabolism. 2nd ed. New York: McGraw-Hill, 1987:1108-9.

18 Ganda OP, Day JL, Soeldner JS, Connon JJ, Gleason RE. Reproducibility and comparative analysis of repeated intravenous and oral glucose tolerance comparative analysis of repe
tests. Diabetes 1978;27:715-25.

19 Olefsky JM, Reaven GM. Insulin and glucose response to identical oral glucose tolerance tests performed forty-eight hours apart. Diabetes 1971;23:449-53.

20 Harding PE, Oakley NW, Wynn V. Reproducibility of oral glucose tolerance data in normal and mildly diabetic subjects. Clin Endocrinol (Oxf) 1973;2: $387-95$.

21 Knowler WC, Pettitt DJ, Savage PJ, Bennett PH. Diabetes incidence in Pim Indians: contributions of obesity and parental diabetes. Am $\mathcal{J}$ Epidemio $1981 ; 113: 144-56$

22 Wilson PW, McGee DL, Kannel WB. Obesity, very low density lipoproteins and glucose intolerance over fourteen years: the Framingham study. $A m \mathcal{F}$ Epidemiol 1981;114:697-704.
23 Modan M, Karasik A, Halkin H, et al. Effect of past and concurrent body mass index on prevalence of glucose intolerance and type 2 (non-insulindependent) diabetes and on insulin response: the Israel study of glucose intolerance, obesity and hypertension. Diabetologia 1986;29:82-9.

24 Kashiwagi A, Bogardus C, Lillioja S, et al. In vitro insensitivity of glucose transport and antilipolysis to insulin due to receptor and post receptor than abnormalities in obese 7

25 Amatruda JM, Livingston JN, Lockwood DH. Cellular mechanisms in selected states of insulin resistance: human obesity, glucocorticoid excess, and chronic renal failure. Diabetes Metab Rev 1985;1:293-317.

26 Lillioja S, Young AA, Cutler CL, et al. Skeletal muscle capillary density and fiber type are possible determinants of in vivo insulin resistance in man. J Clin Invest 1987;80:415-24.

(Accepted 7 September 1988)

\title{
Physical activity and calcium intake in fracture of the proximal femur in Hong Kong
}

\author{
E Lau, S Donnan, D J P Barker, C Cooper
}

\begin{abstract}
In Hong Kong physical activity and calcium intake of 400 Chinese men and women with hip fractures were compared with those of $\mathbf{8 0 0}$ controls. Daily walking outdoors, upstairs, uphill, or with a load protected against fracture. This was independent of cigarette smoking and alcohol consumption. Higher levels of reported activity in middle life were also protective. Average calcium intake was around one quarter that in Britain because of the low consumption of dairy products. Differences in calcium intake depended mainly on consumption of green vegetables and small fish. High intake protected against hip fracture.

These findings point to the importance of maintaining daily physical activity and calcium intake in urbanised Chinese populations.
\end{abstract}

\section{Introduction}

Hip fractures are an increasing public health problem among elderly Chinese in Hong Kong. ${ }^{12}$ This population eats a traditional Chinese diet, which is low in calcium, and urbanisation has reduced their physical activity. The contribution of these two factors to the rising incidence of fracture is unknown. We compared calcium intake and activity in elderly Chinese men and women with hip fractures and controls of similar ages.

\section{Patients and methods}

The study group comprised 400 patients with radiologically diagnosed hip fracture who were admitted consecutively to the orthopaedic wards of two main hospitals in Kowloon. Their activity and diet were compared with those of two sets of controls. Hospital controls comprised surgical inpatients from the wards of the same hospital. No diagnostic groups were excluded, and the first patient admitted after the case of the same sex and within five years of age was recruited. Community controls came from two sources. For patients aged over 70 they were systematically sampled from a register for the old age allowance in Shatin; for patients aged under 70 controls were randomly selected from attenders at the Chinese University general practice unit in Shatin. Community controls were individually matched to the patients by sex and five year age group. When a control refused to participate a substitute was selected.

All patients in the study group and controls were interviewed by one of two trained interviewers with a structured questionnaire. They were asked about their history of falling, cigarette smoking, and alcohol consumption. The usual frequency of carrying out various forms of weight bearing physical activity was assessed by inquiring about the frequency of walking outdoors, upstairs, uphill, and with a load during the six weeks before admission to hospital. The frequencies of walking uphill and with a load at around the age of 35 were used as indices of past physical activity. Current calcium intake was assessed from the weekly frequency of consumption of nine foods that contain calcium and are commonly eaten in the Chinese diet. The intake was calculated from the calcium content of each food, typical portion sizes, and the frequency of consumption in a week. The results tended to underestimate the total intake.

The data were analysed with a conditional multiple logistic regression for matched case-control studies. As the estimates of relative risk when patients in the study group were compared with community controls were similar to those obtained when they were compared with hospital controls the two control groups were amalgamated.

\section{Results}

Eighteen patients could not be interviewed because of their poor mental state, and additional patients were recruited to make up 400 . The rate of response among the controls was $90 \%$. Table I shows the age and sex distribution of the patients in the study group. There were more older women, and the totals were 280 women and 120 men. Significant increases in the risk of hip fracture were found in people who were current or previous cigarette smokers (relative risk $=1 \cdot 3,95 \%$ confidence interval 1.0 to $1 \cdot 7$ ), who consumed alcohol daily $(3.9,2 \cdot 3$ to $6 \cdot 7)$, and who had reported a fall within the previous year $(1 \cdot 8,1 \cdot 3$ to $2 \cdot 5)$.

Table II shows the relation between current physical activity and the relative risk of hip fracture. Among women the risk was up to $2 \cdot 1$ times greater in those who reported walking outdoors, upstairs, uphill, or with a load less than once a day. After adjustment for cigarette smoking and alcohol consumption the TABLE I-Age and sex distribution of patients with hip fracture

\begin{tabular}{lcr}
\hline Age (years) & Women & Men \\
\hline$<70$ & 54 & 47 \\
$70-79$ & 108 & 45 \\
$\geqslant 80$ & 118 & 28 \\
\hline Total & 280 & 120 \\
\hline
\end{tabular}

Correspondence to: Dr Lau.

\author{
D J P Barker, FRCP, director \\ C Cooper, MRCP, \\ epidemiologist \\ Department of Community
Medicine, Chinese \\ University of Hong Kong, \\ Hong Kong \\ Epidemiolog Unit, \\ Southampton, \\ Southampton General \\ Hospital, Southampton
}




\begin{tabular}{|c|c|c|c|c|c|c|c|c|c|c|}
\hline \multirow[b]{3}{*}{ Frequency of activity } & \multicolumn{5}{|c|}{ Women } & \multicolumn{5}{|c|}{ Men } \\
\hline & \multirow[b]{2}{*}{$\begin{array}{l}\text { No of } \\
\text { patients }\end{array}$} & \multirow[b]{2}{*}{$\begin{array}{c}\text { No of } \\
\text { controls }\end{array}$} & \multicolumn{3}{|c|}{ Relative risk } & \multirow[b]{2}{*}{$\begin{array}{c}\text { No of } \\
\text { patients }\end{array}$} & \multirow[b]{2}{*}{$\begin{array}{c}\text { No of } \\
\text { controls }\end{array}$} & \multicolumn{3}{|c|}{ Relative risk } \\
\hline & & & $\begin{array}{c}\text { Non- } \\
\text { adjusted }\end{array}$ & Adjusted $t$ & $\begin{array}{c}95 \% \\
\text { Confidence } \\
\text { interval }\end{array}$ & & & $\begin{array}{c}\text { Non- } \\
\text { adjusted }\end{array}$ & Adjusted $\dagger$ & $\begin{array}{c}95 \% \\
\text { Confidence } \\
\text { interval }\end{array}$ \\
\hline \multicolumn{11}{|l|}{ Walking outdoors: } \\
\hline Less than once a day & 105 & 151 & 1.7 & 1.7 & $1 \cdot 2$ to $2 \cdot 3$ & 25 & 40 & $1 \cdot 3$ & $1 \cdot 3$ & 0.7 to 2.4 \\
\hline Once daily or more & 175 & 409 & 1.0 & 1.0 & & 95 & 200 & 1.0 & 1.0 & \\
\hline \multicolumn{11}{|l|}{ Walking upstairs: } \\
\hline Less than once a day & 182 & 323 & 1.4 & 1.4 & 1.0 to 1.9 & 71 & 133 & $1 \cdot 2$ & 1.0 & 0.6 to 1.7 \\
\hline Once daily or more & 97 & 235 & 1.0 & 1.0 & & 49 & 107 & 1.0 & 1.0 & \\
\hline \multicolumn{11}{|l|}{ Walking uphill: } \\
\hline Less than once a day & 267 & 523 & 1.5 & 1.6 & 0.8 to 3.1 & 111 & 216 & 1.4 & 1.9 & 0.7 to 4.7 \\
\hline Once daily or more & 13 & 37 & $1 \cdot 0$ & 1.0 & & 9 & 24 & 1.0 & 1.0 & \\
\hline \multicolumn{11}{|l|}{ Walking with a load: } \\
\hline Less than once a day & 268 & 513 & $2 \cdot 1$ & $2 \cdot 3$ & $1 \cdot 2$ to 4.7 & 111 & 218 & $1 \cdot 3$ & $1 \cdot 4$ & 0.6 to 3.3 \\
\hline Once daily or more & 11 & 45 & $1 \cdot 0$ & 1.0 & & 9 & 22 & 1.0 & 1.0 & \\
\hline
\end{tabular}

*Information was not available for all subjects.

†Adjusted for cigarette smoking and alcohol consumption.

TABLE III - Past physical activity and risk of hip fracture in 400 patients with hip fracture and 800 controls

\begin{tabular}{|c|c|c|c|c|c|c|}
\hline \multirow[b]{2}{*}{ Frequency of activity } & \multirow[b]{2}{*}{$\begin{array}{c}\text { No of } \\
\text { patients }\end{array}$} & \multirow[b]{2}{*}{$\begin{array}{c}\text { No of } \\
\text { controls }\end{array}$} & \multicolumn{4}{|c|}{ Relative risk } \\
\hline & & & $\begin{array}{c}\text { Non- } \\
\text { adjusted }\end{array}$ & $\begin{array}{c}95 \% \\
\text { Confidence } \\
\text { interval }\end{array}$ & Adjusted $\dagger$ & $\begin{array}{c}95 \% \\
\text { Confidence } \\
\text { interval }\end{array}$ \\
\hline & & & men & & & \\
\hline \multicolumn{7}{|l|}{ Walking uphill: } \\
\hline Less than once a day & 53 & 154 & $1 \cdot 6$ & $1 \cdot 1$ to $2 \cdot 2$ & 1.6 & $1 \cdot 1$ to $2 \cdot 3$ \\
\hline Once daily or more & 227 & 406 & 1.0 & & 1.0 & \\
\hline \multicolumn{7}{|l|}{ Walking with a load: } \\
\hline Less than once a day & 126 & 272 & $1 \cdot 2$ & 0.9 to 1.5 & $1 \cdot 2$ & 0.9 to 1.6 \\
\hline \multirow[t]{2}{*}{ Once daily or more } & 153 & 286 & $1 \cdot 0$ & & $1 \cdot 0$ & \\
\hline & \multicolumn{2}{|c|}{ Walking uphill: } & Ien & & & \\
\hline Less than once a day & 19 & 51 & 1.5 & 0.8 to 2.8 & 1.5 & 0.8 to 2.9 \\
\hline Once daily or more & 101 & 189 & 1.0 & & $1 \cdot 0$ & \\
\hline \multicolumn{7}{|l|}{ Walking with a load: } \\
\hline Less than once a day & 38 & 103 & 1.6 & $1 \cdot 0$ to $2 \cdot 6$ & 1.7 & $1 \cdot 1$ to $2 \cdot 8$ \\
\hline Once daily or more & 82 & 137 & 1.0 & & $1 \cdot 0$ & \\
\hline
\end{tabular}

*Information was not available for all subjects.

†Adjusted for cigarette smoking and alcohol consumption.

TABLE IV - Dietary calcium intake and risk of hip fracture in 400 patients with hip fracture and 800 controls

\begin{tabular}{|c|c|c|c|c|c|c|}
\hline \multirow{2}{*}{$\begin{array}{l}\text { Fifths of the } \\
\text { distribution of } \\
\text { calcium intake } \\
(\mathrm{mg} / \text { day })\end{array}$} & \multirow[b]{2}{*}{$\begin{array}{c}\text { No of } \\
\text { patients }\end{array}$} & \multirow[b]{2}{*}{$\begin{array}{l}\text { No of } \\
\text { controls }\end{array}$} & \multicolumn{4}{|c|}{ Relative risk } \\
\hline & & & $\begin{array}{l}\text { Non- } \\
\text { adjusted }\end{array}$ & $\begin{array}{c}95 \% \\
\text { Confidence } \\
\text { interval }\end{array}$ & Adjusted $†$ & $\begin{array}{c}95 \% \\
\text { Confidence } \\
\text { interval }\end{array}$ \\
\hline \multicolumn{7}{|c|}{ Women } \\
\hline$<75$ & 93 & 137 & 1.9 & $1 \cdot 2$ to $2 \cdot 9$ & 1.9 & 1.2 to 2.9 \\
\hline $75-$ & 47 & 72 & 1.8 & $1 \cdot 1$ to 3.0 & 1.9 & $1 \cdot 1$ to $3 \cdot 1$ \\
\hline $83-$ & 42 & 105 & $1 \cdot 1$ & 0.7 to 1.9 & $1 \cdot 1$ & 0.7 to 1.9 \\
\hline 129 & 57 & 126 & $1 \cdot 3$ & 0.8 to 2.0 & $1 \cdot 2$ & 0.8 to 2.0 \\
\hline$\geqslant 244$ & 41 & 120 & 1.0 & & 1.0 & \\
\hline & \multicolumn{6}{|c|}{ Men } \\
\hline 75 & 14 & $\begin{array}{l}67 \\
30\end{array}$ & 2.0 & $1 \cdot 1$ to $3 \cdot 7$ & $\begin{array}{l}2 \cdot 1 \\
1 \cdot 4\end{array}$ & $\begin{array}{l}1.1 \text { to } 4.2 \\
0.6 \text { to } 3.4\end{array}$ \\
\hline $83-$ & 23 & $\begin{array}{l}30 \\
44\end{array}$ & $\begin{array}{l}1.4 \\
1.6\end{array}$ & $\begin{array}{l}0.0 \text { to } 3.2 \\
0.8 \text { to } 3.2\end{array}$ & 1.7 & 0.8 to 3.7 \\
\hline 129- & 20 & 40 & 1.5 & 0.7 to 3.2 & 1.5 & 0.7 to 3.2 \\
\hline$\geqslant 244$ & 19 & 59 & 1.0 & & 1.0 & \\
\hline
\end{tabular}

^Adjusted for cigarette smoking and alcohol consumption.

increased risks associated with all these activities remained significant $(p=0.05)$ except for that associated with walking uphill. Among men, after adjustment, increased risks were associated with walking outdoors, uphill, or with a load less than once a day. These were not significant.

Table III shows the relation between past physical activity and the relative risk of fracture. Among women a significant increase in risk associated with walking uphill less often than once a day remained after adjustment for smoking and alcohol $(p<0 \cdot 05)$. For men a significant increase in risk associated with walking with a load less than once a day also remained after adjustment $(\mathrm{p}<0.05)$.

The mean daily calcium intake of the patients in the study group was lower than that of the controls. The intake was $128 \mathrm{mg}$ in female patients (interquartile range $75-176 \mathrm{mg}$ ) compared with $168 \mathrm{mg}$ in female controls $(76-214 \mathrm{mg}$ ) and $141 \mathrm{mg}$ in male patients (75-164 mg) compared with $177 \mathrm{mg}$ in male controls (75-226 mg). Table IV shows a fall in relative risk of hip fracture with increasing calcium intake in women and men. This trend remained significant after adjustment for cigarette smoking and alcohol intake in women $\left(\chi^{2}=21.4, \mathrm{df}=1, \mathrm{p}<0.01\right)$ and men $\left(\chi^{2}=4.4, \mathrm{df}=1\right.$, $\mathrm{p}=0.036)$. In the logistic regression the trends in risk with physical activity and calcium intake were independent of each other.

\section{Discussion}

We showed that among elderly women in Hong Kong regular daily weight bearing activity and a higher dietary calcium intake were associated with a reduced risk of hip fracture. Among elderly men there was a similarly strong relation with calcium intake but the relation with activity was not significant.

The rates of response for both patients and controls were high. There were, nevertheless, potential sources of bias in both sets of controls. The hospital control group may have overrepresented people with an inactive lifestyle and atypical diet, whereas the community control group may have been biased towards fitter individuals who had moved out of Kowloon to a newly built suburb. The differences in physical activity and calcium intake between patients and controls were, however, similar for both control groups.

In 1970 Chalmers and Ho suggested that hard physical labour might be the factor that protected the Bantu, the Singaporean, and the Hong Kong Chinese against hip fracture. ${ }^{4}$ The increasing incidence of hip fracture that has been shown in the Chinese population of Hong Kong could be the result of rapid urbanisation and a reduction in weight bearing physical activity. ${ }^{12}$

The mean daily intake of calcium was low in both patients and controls in comparison with Britain. The estimated daily intake among controls was $171 \mathrm{mg}$ compared with $689 \mathrm{mg}$ in a population of similar age in Southampton (see accompanying paper, $p$ 1443). There was little overlap in the two distributions. Calcium intake in Hong Kong was assessed from only nine food items and will have been underestimated. This, however, is unlikely to account for the large difference from Britain. Low calcium intake is a known characteristic of the Chinese diet, ${ }^{2}$ in which consumption of dairy products is low. Rice is eaten with one or two other dishes in every meal in the traditional Chinese diet. These dishes can be of mixed (such as meat fried with green vegetables) or single ingredients (such as steamed fish); $78 \%$ of patients and $81 \%$ of controls ate green vegetables daily; $17 \%$ of patients and $27 \%$ of controls reported that they ate small fish at least once a 
week. Soya bean curd, which is an important potential source of calcium in the Chinese diet, was eaten at least once a week by $35 \%$ of controls but by only $27 \%$ of patients. In contrast to the data from Southampton, calcium was found to protect against fracture in both women and men. In the past low calcium intake might have been offset by a high level of weight bearing physical activity, which maintained bone mass. The decline in activity which followed the construction of high rise apartments and the disappearance of walking space may have unmasked the adverse skeletal effect of a low calcium intake.

Public health strategies to reduce the rising incidence of hip fractures in urbanising oriental populations are urgently required. Our results point to the importance of maintaining physical activity and calcium intake in elderly Chinese people who grew up in rural communities, characterised by high levels of physical activity and a diet low in calcium, but are now mostly living in flats in high rise buildings while continuing to eat a traditional diet.

This study was supported by a grant from the Wellcome Trust. We acknowledge Dr Y Chow and Dr D Lau of Queen Elizabeth Hospital and Dr P C Lee of Kwong Wah Hospital for their help in recruiting patients. We thank Miss R To and Mrs F Cheng, who interviewed the subjects; Mr A Cheang, who helped with the analysis; and Mrs P Tam and Mrs B Wilde for the secretarial support.

1 Lau EMC, Donnan SPB. Physical labour and fractured proximal femur in Chinese. Am J Epidemiol 1987;126:753.

Pun KK, Young RTT. Osteoporosis - the silent epidemic. JAMA (South East Asian edition) 1987; Oct:5-6.

3 Food and agriculture organisation. Food composition table for use in East Asia. Rome: FAO, 1972 .

4 Chalmers J, Ho KC. Geographical variations in senile osteoporosis. The association with physical activity. I Bone foint Surg $[B r]$ 1970;52:667-75.

(Accepted 20 September 1988)

\title{
Physical activity, muscle strength, and calcium intake in fracture of the proximal femur in Britain
}

\author{
C Cooper, D J P Barker, C Wickham
}

\begin{abstract}
Regular exercise and high calcium intake possibly help to preserve bone mass. Little is known, however, about their role in preventing hip fracture. The physical activity and calcium intake of $\mathbf{3 0 0}$ elderly men and women with hip fractures were compared with those of 600 controls matched for age and sex. In both sexes increased daily activity, including standing, walking, climbing stairs, carrying, housework, and gardening protected against fracture. This was independent of other known risk factors, including body mass, cigarette smoking, and alcohol consumption. Strength of grip correlated with activity and was inversely related to the risk of fracture. Calcium intake was not related to the risk of fracture in women. Men with daily calcium intakes above $1 \mathrm{~g}$ had lower risks.

These findings point to the importance of elderly people in Britain maintaining physical activity in their day to day lives.
\end{abstract}

\section{Introduction}

Hip fractures in elderly people are an important public health problem. Osteoporosis and falls are two known aetiological factors. ${ }^{1}$ Regular exercise and high calcium intake, measures that possibly preserve bone mass, ${ }^{2}$ offer the main immediate population based strategy for preventing osteoporosis. Little information, however, is available about their role in preventing hip fracture, ${ }^{3}$ and hence no scientific basis exists for recommending them as part of a national preventive campaign. We used validated methods to compare physical activity and calcium intake in a series of elderly patients with hip fractures and community controls. We measured the independent contribution of each of these two factors to the risk of hip fracture after allowing for the confounding effects of other known risk factors, which include low body mass, cigarette smoking, and alcohol consumption. ${ }^{3}$

\section{Patients and methods}

We recruited 473 patients aged 50 and over who lived in Southampton health district and were admitted sequentially to the orthopaedic wards of this hospital. Fifteen patients died before they could be approached, and 12 declined to participate. The remaining 446 completed a 10 point Hodkinson abbreviated mental test score, ${ }^{+}$and the 300 patients ( 240 women and $60 \mathrm{men}$ ) who scored more than 6 became the study group. We estimated that a study of this size had a $90 \%$ power of detecting a relative risk of 1.7 or more in women and 3.0 or more in men at the five per cent level of significance, assuming a $30 \%$ exposure of the controls to a dichotomous risk factor.

Patients in the study group were compared with 600 community controls, resident in the same district, who were selected from the register of Hampshire Family Practitioner Committee. Controls were individually matched to the patients in the study group by sex and age within four years. The rate of response among controls was $71 \%$ of those contacted. When a control refused to participate or failed the mental test score a substitute was selected.

All patients in the study group and the controls were interviewed by one of three trained interviewers. Each case-control set was seen by the same interviewer. Patients were interviewed in hospital within ten days of admission. Controls were interviewed within three months of their matched patient $(68 \%)$ or during the corresponding quarter a year later (32\%).

Physical activity in the six weeks before the interview was estimated with a validated questionnaire for the assessment of customary activity in the elderly. ${ }^{5}$ Five indices of current activity were derived: self reported walking speed, time spent standing indoors, time spent walking outdoors, frequency of muscle loading activity such as climbing stairs or carrying loads, and time spent in productive activities such as gardening and housework.

Current calcium intake was measured with a frequency and amount questionnaire, which obtained information about the consumption of six food items: milk, bread, cheese, puddings, cakes, and biscuits. A Department of Health survey of elderly people in Britain suggested that $87 \%$ of their total calcium intake was derived from these food items. ${ }^{6}$ We have shown previously that estimates of calcium intake with this questionnaire correlate well with those derived from 